\title{
BMJ Open Association between cellphone use while driving legislation and self- reported behaviour among adult drivers in USA: a cross-sectional study
}

Toni Marie Rudisill, ${ }^{1}$ Motao Zhu, ${ }^{2}$ Haitao $\mathrm{Chu}^{3}$

To cite: Rudisill TM, Zhu M, Chu $\mathrm{H}$. Association between cellphone use while driving legislation and self-reported behaviour among adult drivers in USA: a crosssectional study. BMJ Open 2019;9:e023456. doi:10.1136/ bmjopen-2018-023456

- Prepublication history and additional material for this paper are available online. To view these files, please visit the journal online (http://dx.doi. org/10.1136/bmjopen-2018023456).

Received 6 April 2018

Revised 12 November 2018 Accepted 23 November 2018

D Check for updates

C Author(s) (or their employer(s)) 2019. Re-use permitted under CC BY-NC. No commercial re-use. See rights and permissions. Published by BMJ.

${ }^{1}$ Epidemiology, West Virginia University, Morgantown, West Virginia, USA

${ }^{2}$ Center for Injury Research and Policy, The Research Institute at Nationwide Children's Hospital, Columbus, Ohio, USA

${ }^{3}$ Division of Biostatistics, University of Minnesota, Minneapolis, Minnesota, USA

Correspondence to Dr Motao Zhu;

Motao.Zhu@

nationwidechildrens.org

\section{ABSTRACT}

Objectives Cellphone use behaviours can vary demographically in the USA. This study examined whether legislation restricting cellphone use while driving was associated with lower self-reported hand-held cellphone conversations or texting behaviours among adult drivers of different ages (19-24, 25-39, 40-59, $\geq 60$ years), sex, race/ethnicity (white non-Hispanic, black non-Hispanic, Hispanic, Other) or rurality (urban, rural).

Design Cross-sectional study.

Setting USA.

Participants Individuals $\geq 19$ years of age who indicated they were a current driver and participated in the 20112014 Traffic Safety Culture Index Surveys $(n=9706)$. Primary outcome The exposure was the presence of a hand-held calling or texting ban applicable to all drivers (ie, universal) at time of survey. Modified Poisson regression with robust SE was used to estimate the risk of engaging in these self-reported behaviours.

Results In fully adjusted models, universal texting bans were not associated with lower texting behaviours (adjusted risk ratio $[\mathrm{aRR}]=0.92 ; 95 \% \mathrm{Cl} 0.84,1.01$ ). In stratified, fully adjusted models, men and those of other racial/ethnic origin were $13 \%$ and $33 \%$ less likely, respectively $(\mathrm{aRR}=0.87 ; 95 \% \mathrm{Cl} 0.77,0.98$; $\mathrm{aRR}=0.67$; $95 \% \mathrm{Cl} 0.46,0.97)$, to engage in texting behaviours if a universal texting ban was effective in their state. Conversely, universal hand-held calling bans were associated with lower self-reported hand-held cellphone conversations across every sub-group. In fully adjusted models, the presence of a hand-held calling ban was associated with $40 \%$ lower (aRR $=0.60,95 \% \mathrm{Cl} 0.54,0.67$ ) self-reported hand-held cellphone conversations while driving.

Conclusions Universal hand-held calling bans were associated with lower self-reported cellphone conversations for adult drivers. More interventional work targeting adult drivers may be needed to reduce texting while driving.

\section{INTRODUCTION}

Cellphone use while driving is a prevalent phenomenon in the USA as $>90 \%$ of the population owns a cellphone. ${ }^{1}$ National roadside observations of drivers show that at any given moment, over 587000 drivers are

\section{Strengths and limitation of this study}

- This study utilised self-reported cellphone use while driving data from adult drivers from all 50 states in the USA.

- Self-reported behaviours may not necessarily translate into what drivers actually 'do' while driving.

Drivers may have purposefully biased their responses to be more socially acceptable.

D Due to the cross-sectional nature of this study, causality cannot be determined.

interacting with cellphones. ${ }^{2}$ A 2010 national survey of drivers found that $77 \%$ of respondents self-reported answering cellphone calls, $41 \%$ made calls, $10 \%$ read texts and $6 \%$ sent texts or emails on the majority of driving trips. ${ }^{3}$ Experimental and observational studies have consistently shown that cellphone interactions place additional cognitive, visual and manual demands on drivers. ${ }^{4-8}$ Furthermore, many admit that sending or reading text messages and talking on hand-held cellphones are the most distracting tasks to perform while driving. ${ }^{9}$

To curtail these behaviours, many states have passed legislation. As of August 2017, 14 states and the District of Columbia (DC) have enacted universal hand-held calling bans, which bar hand-held phone conversations among drivers. ${ }^{10}$ The term 'universal' indicates that the law applies to all licensed drivers. Additionally, 46 states and DC have ratified universal texting while driving bans, which ban drivers from reading or sending text-based messages. ${ }^{10}$ Furthermore, 37 states and DC have enacted bans prohibiting any cellphone use for young or novice drivers. ${ }^{10}$

Numerous studies have investigated the relationship between cellphone legislation and driver behaviour. Typically, these studies involve actual road-side observations of drivers at controlled intersections or self-reported 
behaviour. To the authors' knowledge, nine studies have investigated the relationship between cellphone legislation and road-side observed driver behaviour in the USA; most studies concluded that universal hand-held bans were associated with lower observed phone conversations among drivers. ${ }^{11-19}$ One study found that universal texting bans were associated with less hand-held device manipulation among observed drivers. ${ }^{11}$ As for self-reported driver behaviour, five studies have investigated this relationship, but three applied to young drivers. ${ }^{20-24}$ A telephone survey of randomly sampled US drivers revealed that daily cellphone conversations were $13 \%$ among drivers in states with universal hand-held bans and 22\% among drivers in states without universal handheld bans. ${ }^{20}$ The percentage of drivers never talking on a cellphone while driving was higher in states with universal hand-held bans (44\%) compared with those in states without these bans (30\%). ${ }^{20}$ Another study, which was conducted in Georgia, investigated the self-reported texting behaviours among healthcare providers pre and post passage of the state's universal texting ban. ${ }^{21}$ The study found that $68 \%$ of respondents did not change their behaviour, while $32 \%$ texted less after the law's enactment. $^{21}$

While these bans may influence driver behaviour, there are still extant gaps in the literature. First, traffic safety research has shown differences between observed and self-reported driver behaviour. ${ }^{25-27}$ While universal handheld bans have been associated with lower phone conversations across all demographics (sex, age, race/ethnicity and rural/urban location) of observed drivers, ${ }^{18}$ this has not been fully explored using self-reported data. ${ }^{24}$ It is known that traffic safety behaviours, in general, can vary by driver age, sex, race/ethnicity and rurality. ${ }^{32-33}$ It is also known that general cellphone use behaviours may vary by age, sex and race/ethnicity. ${ }^{34}$ Second, the relationship between universal texting and hand-held bans and self-reported behaviour has not been fully investigated in national sample of adults; it has been done in young drivers. ${ }^{24}$ Lastly, many states have recently enacted cellphone legislation so previous findings need to be updated. $^{10}$

Therefore, the purpose of this study was to investigate whether universal hand-held calling bans were associated with lower self-reported hand-held phone conversations and if universal texting bans were associated with lower self-reported texting while driving among adult drivers (ie, $\geq 19$ years) of different ages, sex, race/ethnicity and location. ${ }^{24}$ The hypotheses were: (1) that hand-held cellphone bans would be associated with lower self-reported behaviours in most groups and (2) universal texting bans would not be associated with lower texting in groups known to engage in these behaviours (ie, younger adult drivers and men). In this paper, the term 'cellphone use' implies hand-held cellphone conversations and reading/ sending text-based messages.

\section{METHODS}

\section{Data sources}

The primary data sources for this cross-sectional analysis were the 2011-2014 Traffic Safety Culture Index surveys. Since 2005, this survey has been sponsored annually by the American Automobile Association Foundation for Traffic Safety; the purpose of the survey is to assess the traffic safety culture of road users across the USA. The survey asks questions pertaining to self-reported driving behaviours and personal opinions towards various traffic safety topics. Respondents include both drivers and non-drivers. A panel comprised of $\sim 58000$ individuals $\geq 16$ years of age exists and participants are obtained through a stratified random sample. This panel is nationally representative of USA and households reachable by telephone or regular mail. Drivers $\leq 18$ years of age are occasionally recruited through parents/guardians who are panel members. The survey is weighted for this sampling and non-response. Approximately 3000 individuals participate in the survey each year. Participants are from all 50 states. Additional details regarding the survey have been described elsewhere. ${ }^{245}$

In addition to the surveys, legislative data were compiled by the study authors. The authors conducted numerous internet searches to discern which states had cellphone legislation in effect from 1 January 2011 through 31 December 2014. ${ }^{103637}$ Each individual law was researched, retrieved from the states' legislative archives, read and coded. Resultantly, a data set was constructed containing information such as the type of law, who the law applied to and the effective dates. Two individuals independently coded the legislation for accuracy. The legislative data were then merged with the survey data by the drivers' states of residence. Online supplementary appendix table A1 lists the effective dates of both universal bans by state.

\section{Patient and public involvement}

This study utilised data that was previously collected by the American Automobile Association Foundation for Traffic Safety; no patients/participants interacted with the study authors.

\section{Study population}

Because this analysis focused on adult drivers, the study population was limited to individuals $\geq 19$ years of age that reported being a current driver at time of survey. ${ }^{24}$

\section{Variables}

The two outcomes of interest were texting behaviours and hand-held cellphone conversations while driving. On the surveys, two questions regarding texting behaviours were asked (eg, In the past 30 days, how often have you read a text message or email while you were driving; in the past 30 days, how often have you typed or sent a text message or email while you were driving). The response options included: regularly, fairly often, rarely, just once and never. These response options were dichotomised. A response of 'never' was categorised 
as 'no', and other response options noted were categorised as 'yes'. Responses to both of these questions were then combined to form the text messaging variable, overall. Therefore, if a respondent answered 'never' to both questions, the overall response was 'no', whereas if they indicated any other frequency to either question, the overall response was 'yes'. For hand-held phone use while driving, two questions were asked on the 2012-2014 surveys (note: the questions pertaining to hand-held cellphone conversations differed on the 2011 survey so those responses were not included in the analysis pertaining to hand-held conversations only). The first question asked, 'In the past 30 days, how often have you talked on a cellphone while you were driving (count any type of phone including Bluetooth, speaker phone, etc.)?' The response options included regularly, fairly often, rarely, just once and never. A follow-up question was then asked of those who did not refuse the question and did not answer with a response of 'never'. This question asked, 'When you talk on your cellphone while driving, do you usually hold the phone in your hand or do you use a hands-free device?' The response options to this question were: I always hold the phone in my hand, I usually hold the phone in my hand, I hold the phone in my hand about half the time and use a hands-free device about half of the time, I usually use a hands-free device, I always use a hands-free device. The responses to these questions were combined to form the overall hand-held cellphone variable, which was dichotomised. Those answering the first question as 'never' or the second question as always using a hands-free device were considered to not engage in hand-held cellphone conversations. Those answering the second question at any other frequency were considered to engage in handheld cellphone conversations.

The primary independent variables of interest were whether or not a universal hand-held calling ban or universal texting ban were in effect in the respondent's state of residence at the time the respondent took the survey. Both outcomes were dichotomised. Other covariates included driver's age, sex, race/ethnicity, location, region, marital status, education and household income. The categorisation of these variables are depicted in table 1. Location was based on whether the respondent lived in a metropolitan statistical area (MSA). MSAs are determined by the USA Census Bureau and delineate the degree of urbanisation in an area. The survey panel notates whether a person lives in a designated MSA based on their address at the time of survey. Those living in a MSA were considered 'urban' and those not living in a MSA were categorised as 'rural'. Drivers' marital status was categorised as married/living with a partner or other, which included those who were divorced, widowed, separated or never married.

\section{Statistical analyses}

Frequencies and percentages of driver demographics were assessed. The analysis was stratified by each demographic group and risk ratios were estimated using modified Poisson regression with robust SE accounting
Table 1 Demographic characteristics of drivers $\geq 19$ years of age: 2011-2014 Traffic Safety Culture Index Survey $(\mathrm{n}=9706)$

\begin{tabular}{|c|c|c|}
\hline Characteristic & $\mathbf{N}^{*}$ & $\% \dagger$ \\
\hline \multicolumn{3}{|l|}{ Age (in years) } \\
\hline $19-24$ & 692 & 9.1 \\
\hline $25-39$ & 2211 & 27.6 \\
\hline $40-59$ & 3847 & 37.4 \\
\hline$\geq 60$ & 2956 & 25.8 \\
\hline \multicolumn{3}{|l|}{ Sex } \\
\hline Men & 4835 & 49.1 \\
\hline Women & 4871 & 50.9 \\
\hline \multicolumn{3}{|l|}{ Race/Ethnicity } \\
\hline White, Non-Hispanic & 7290 & 69.0 \\
\hline Black, Non-Hispanic & 814 & 10.7 \\
\hline Hispanic & 1014 & 13.6 \\
\hline Other & 588 & 6.7 \\
\hline \multicolumn{3}{|l|}{ Location } \\
\hline Urban & 8331 & 86.7 \\
\hline Rural & 1304 & 13.3 \\
\hline Missing & 126 & \\
\hline \multicolumn{3}{|l|}{ Marital Status } \\
\hline Married/co-habitation & 6570 & 65.7 \\
\hline Other & 3136 & 34.3 \\
\hline \multicolumn{3}{|l|}{ Education } \\
\hline High school or less & 3479 & 39.2 \\
\hline Some college or more & 6227 & 60.8 \\
\hline \multicolumn{3}{|l|}{ Household Income } \\
\hline$<\$ 50000$ & 3800 & 41.0 \\
\hline$\geq \$ 50000$ & 5906 & 59.0 \\
\hline \multicolumn{3}{|l|}{ Legislation Status } \\
\hline Hand-held ban only & 0 & 0 \\
\hline Texting ban only & 4586 & 47.2 \\
\hline Both bans & 2654 & 27.3 \\
\hline No bans & 2466 & 25.4 \\
\hline
\end{tabular}

*Actual, non-weighted counts.

† May not add to $100 \%$ due to rounding.

for correlation within state; this model was chosen over logistic regression because ORs do not approximate risk ratios if a behaviour is prevalent (i.e. $>10 \%$ ) in a population. ${ }^{38} \mathrm{~A}$ working autoregressive correlation matrix was used for random effects of state. This correlation matrix was chosen due to having multiple state data years over time. All models accounted for survey weighting. Four separate models were run for both outcomes and demographic group. Model 1 contained indicators for the legislative ban of interest. Model 2 controlled for both universal bans and survey year. Model 3, which was the primary analysis, controlled for all variables in Model 
2 and drivers' age group, sex, race/ethnicity, marital status, education and household income as these are known potential confounders in traffic safety research or cellphone behaviours. ${ }^{3}{ }^{34} \mathrm{~A}$ fourth model containing the variables from Model 2, the driver characteristic, and an interaction term between the legislative ban and the driver characteristic were run to formally test for sub-group differences. All analyses were conducted using SAS software, V.9.4, with a two-sided significance level of 0.05 .

\section{RESULTS}

Among those surveyed, 9706 individuals met the inclusion criteria (table 1$)$. The majority of drivers were aged $25-59$ years $(65 \%)$ and slightly more were women $(51 \%)$. Most drivers were of white non-Hispanic race/ethnicity $(69 \%)$ and resided in urbanised areas $(87 \%)$. Many drivers were married/cohabitating with a partner $(66 \%)$, had at least some college education $(61 \%)$ and earned over $\$ 50000$ per year in their household $(59 \%)$. Most drivers were from states where only texting bans were in effect at time of survey (47\%), while $25 \%$ of respondents were from states with no legislation.

Overall, $34 \%$ of drivers read or sent a text message or email while driving in the 30 days prior to survey (table 2). Drivers aged 19-24 and 25-39 years texted more than any other demographic group $(59 \%$ and $56 \%$, respectively). In fully adjusted models, universal texting bans were not associated with less texting behaviours [adjusted (a) $\mathrm{RR}=0.92 ; 95 \% \mathrm{CI}, 0.84,1.01]$. There was evidence of an interaction between sex and texting behaviours ( $p=0.0150)$, but not other driver characteristics. In stratified, fully adjusted models, men and those of other racial/ ethnic origins were $13 \%$ and $33 \%$, respectively, less likely to report engaging in texting behaviours if a universal texting ban was effective in their state $(\mathrm{aRR}=0.87 ; 95 \% \mathrm{CI}$ 0.77 to 0.98 ; $\mathrm{aRR}=0.67,95 \%$ CI 0.46 to 0.97 ).

Hand-held cellphone conversations were reported by $53 \%$ of drivers (table 3). This behaviour was reported more frequently among 19-year to 24-year-olds (66\%), white non-Hispanics (55\%) and rural drivers (55\%). Overall, the presence of a universal hand-held calling ban was associated with $40 \%$ lower $(\mathrm{aRR}=0.60,95 \%$ CI 0.54 , $0.67)$ self-reported hand-held cellphone conversations while driving. Universal hand-held calling bans were associated with lower self-reported hand-held conversations across every driver sub-group. Additionally, there was an interaction between age group and hand-held cellphone conversations $(p=0.0414)$ but not other driver characteristics.

\section{DISCUSSION}

The principal findings of this analysis were that universal texting bans were not associated with lower texting behaviours overall and for most sub-groups, while handheld calling bans were associated with fewer calling behaviours overall and in all demographic sub-groups. The findings concerning universal hand-held calling bans corroborates with both observational and self-reported studies conducted previously. In this analysis, hand-held bans were associated with $\sim 40 \%$ lower self-reported driver phone conversations. Most observational studies suggest that universal hand-held calling bans are associated with 40\%-76\% lower driver hand-held cellphone conversations. ${ }^{11}$ 14-19 Another study using road-side observed data also found that hand-held cellphone conversations were lower across all ages, sexes, races and locations, which was also seen in this analysis. ${ }^{18}$ A previous national study also showed that universal hand-held calling bans were associated with lower self-reported phone conversations among drivers. ${ }^{20}$ Studies conducted in young drivers showed similar findings. ${ }^{24}$

However, the findings concerning universal texting bans align with some studies but not with others. These may be attributed to differences in study population or methodology. One study, which utilised national observational data, found universal texting bans were associated with less driver device manipulation. ${ }^{11}$ A national study using self-reported data similarly showed no association between texting bans and lower texting behaviours across all drivers and drivers of differing age groups (ie, 18-24, 25-29, 30-59, and $\geq 60$ years of age).${ }^{20}$ A study conducted among drivers 18 years and younger that texting bans were not associated with less self-reported texting behaviours. ${ }^{24}$ A study utilising self-reported data found that drivers $>40$ years of age were 2.3 times more likely to self-report lower texting while driving after the passage of Georgia's universal texting ban; that study found no differences by sex. ${ }^{21}$ In the current analysis, no differences were noted between age groups of drivers but were for sex. Additionally, two other studies which investigated self-reported texting while driving behaviours among high-school students showed some differences among racial/ethnic groups, but none for sex. ${ }^{22}{ }^{23}$ One study found that African American and Latino students from states with universal texting bans were $35 \%$ less likely than white non-Hispanics to report texting while driving. ${ }^{23}$ Qiao and Bell found that non-white high school students from states with primary enforcement of universal texting bans were $43 \%$ less likely than whites to self-report texting while driving. ${ }^{22}$ The current study found that after adjusting for covariates, only those categorised as other race/ethnicity reported 33\% less texting while driving when exposed to a universal texting ban. These slight differences may be due to the differences in study population (ie, highschools students vs adult drivers).

Because cellphone behaviours are known to differ in population sub-groups, it was initially hypothesised that sub-groups differences would have been observed for texting behaviours. Based on existing studies, it was hypothesised that universal hand-held calling bans may have been associated with less self-reported phone use overall. ${ }^{1114-1924}$ These hypotheses were true for hand-held calling bans but not for texting legislation. It is possible 
Table 2 Drivers who read or typed a text message or email while driving

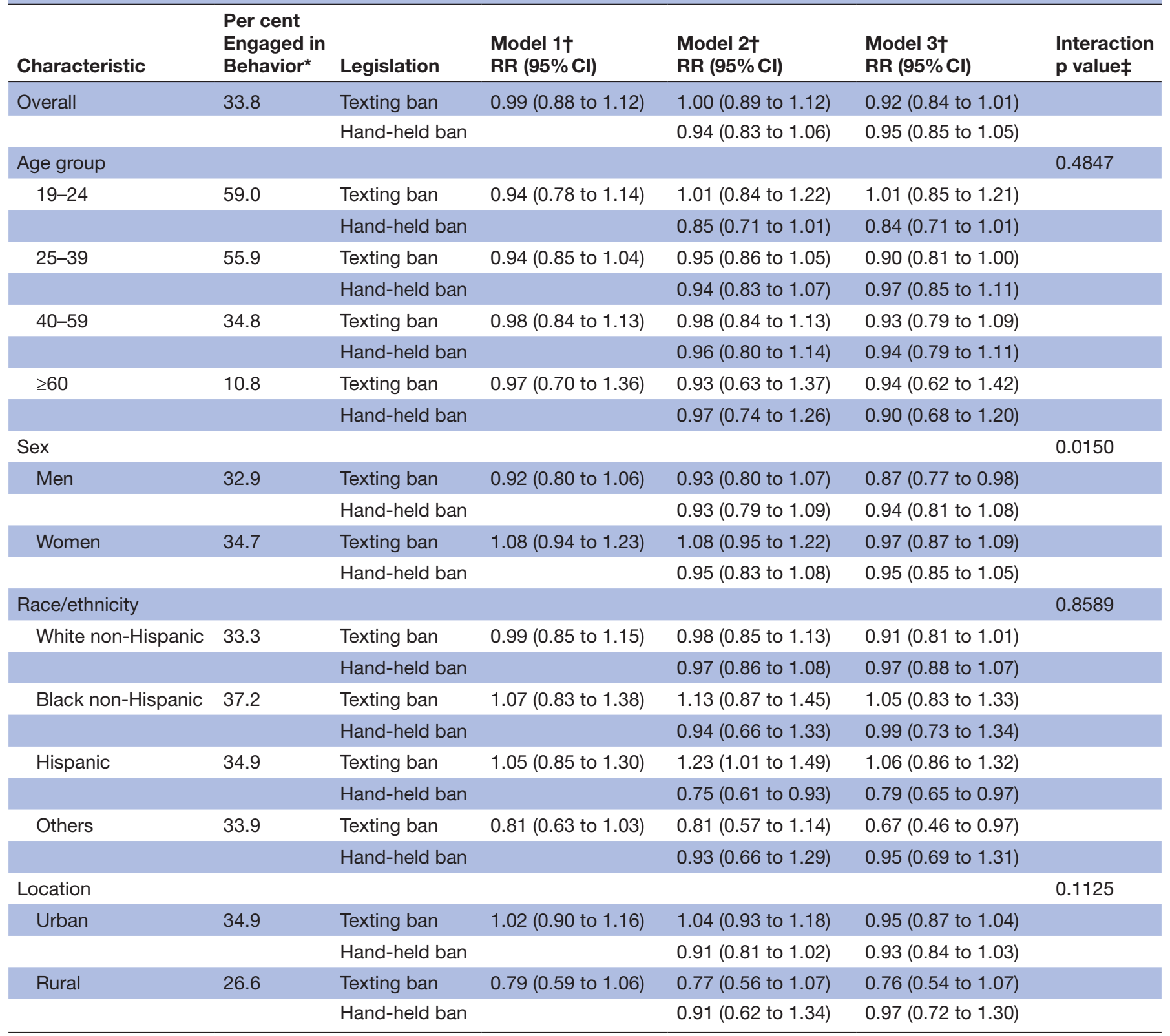

${ }^{*}$ This is the percentage of respondents who reported to engage in the behaviour out of total number who responded to the questions pertaining to texting in the demographic group.

†The outcome was whether or not the driver self-reported reading or typing a text message or email 30 days prior to survey. The exposure was the cellphone legislation. The RR presented compares drivers exposed to the ban to those who were not exposed; while the models contained several variables, only the RR pertaining to the universal texting and universal hand-held ban were shown for ease of presentation. Model 1 contained texting ban (binary) only. Model 2 contained variables for the texting ban (binary), universal hand-held ban (binary) and year of survey. Model 3 contained all terms from Model 2 and additionally controlled for sex, age group, race/ethnicity, marital status, education and household income. In Model 3, if the model was for a particular characteristic it was not adjusted for that characteristic (example: if a model was for male sex, it was not adjusted for sex).

$\ddagger$ A fourth model containing variables from Model 2, the driver characteristic, and an interaction term between the legislative ban and the driver characteristic were run to formally test for sub-group differences. The p-value presented is for the interaction term between the presence of the universal texting ban and the driver characteristic. While the models contained several variables, only the $p$-value was shown for ease of presentation.

$\mathrm{RR}$, estimated risk ratio.

that the uniformity seen across most driver demographic groups was a result of the current cellphone culture in the USA. Cellphone ownership is fairly universal in the US population. ${ }^{1}$ Most states have conducted public safety campaigns regarding the hazards or consequences of cellphone use while driving. ${ }^{39}$ Research suggests that most drivers acknowledge cellphone use while driving can be dangerous and the vast majority support cellphone use 
Table 3 Drivers who conversed on a hand-held cellphone while driving

\begin{tabular}{|c|c|c|c|c|c|c|}
\hline Characteristic & $\begin{array}{l}\text { Per cent } \\
\text { engaged in } \\
\text { behaviour }\end{array}$ & Legislation & $\begin{array}{l}\text { Model } 1 \dagger \\
\text { RR }(95 \% \mathrm{Cl})\end{array}$ & $\begin{array}{l}\text { Model 2† } \\
\text { RR }(95 \% \text { Cl) }\end{array}$ & $\begin{array}{l}\text { Model 3† } \\
\text { RR }(95 \% \mathrm{Cl})\end{array}$ & $\begin{array}{l}\text { Interaction } \\
\text { p valuef }\end{array}$ \\
\hline \multirow[t]{2}{*}{ Overall } & 53.2 & Hand-held ban & 0.61 (0.56 to 0.66 ) & 0.60 (0.55 to 0.66$)$ & 0.60 (0.54 to 0.67$)$ & \\
\hline & & Texting ban & & 1.03 (0.96 to 1.11$)$ & 0.99 (0.92 to 1.06$)$ & \\
\hline Age group & & & & & & 0.0414 \\
\hline \multirow[t]{2}{*}{$19-24$} & 66.1 & Hand-held ban & 0.72 (0.56 to 0.91$)$ & 0.71 (0.56 to 0.89$)$ & 0.77 (0.62 to 0.94$)$ & \\
\hline & & Texting ban & & $1.02(0.92$ to 1.14$)$ & 1.00 (0.89 to 1.12$)$ & \\
\hline \multirow[t]{2}{*}{ 25-39 } & 64.9 & Hand-held ban & 0.64 (0.55 to 0.73 ) & 0.63 (0.55 to 0.73 ) & 0.64 (0.55 to 0.73 ) & \\
\hline & & Texting ban & & 1.01 (0.93 to 1.10$)$ & 0.97 (0.89 to 1.05$)$ & \\
\hline \multirow[t]{2}{*}{$40-59$} & 55.7 & Hand-held ban & 0.62 (0.56 to 0.68 ) & 0.61 (0.55 to 0.67$)$ & 0.60 (0.54 to 0.67$)$ & \\
\hline & & Texting ban & & 1.06 (0.99 to 1.14$)$ & 1.03 (0.95 to 1.12$)$ & \\
\hline \multirow[t]{2}{*}{$\geq 60$} & 38.8 & Hand-held ban & 0.47 (0.39 to 0.57 ) & 0.48 (0.40 to 0.59$)$ & 0.47 (0.37 to 0.59$)$ & \\
\hline & & Texting ban & & 0.91 (0.73 to 1.12$)$ & 0.94 (0.75 to 1.18$)$ & \\
\hline Sex & & & & & & 0.1387 \\
\hline \multirow[t]{2}{*}{ Men } & 53.1 & Hand-held ban & 0.65 (0.56 to 0.74 ) & 0.64 (0.55 to 0.74$)$ & 0.64 (0.54 to 0.75 ) & \\
\hline & & Texting ban & & 1.04 (0.95 to 1.14$)$ & 1.01 (0.91 to 1.11$)$ & \\
\hline \multirow[t]{2}{*}{ Women } & 53.5 & Hand-held ban & 0.57 (0.52 to 0.63 ) & 0.57 (0.52 to 0.62$)$ & 0.57 (0.51 to 0.62 ) & \\
\hline & & Texting ban & & 1.02 (0.92 to 1.13$)$ & 0.97 (0.88 to 1.07$)$ & \\
\hline Race/Ethnicity & & & & & & 0.5244 \\
\hline \multirow[t]{2}{*}{ White non-Hispanic } & 54.5 & Hand-held ban & 0.59 (0.51 to 0.69$)$ & 0.59 (0.51 to 0.68$)$ & 0.59 (0.51 to 0.68$)$ & \\
\hline & & Texting ban & & 1.04 (0.93 to 1.17$)$ & 1.00 (0.92 to 1.10$)$ & \\
\hline \multirow[t]{2}{*}{ Black non-Hispanic } & 50.3 & Hand-held ban & 0.61 (0.45 to 0.83 ) & 0.64 (0.47 to 0.87 ) & 0.63 (0.46 to 0.88$)$ & \\
\hline & & Texting ban & & 0.86 (0.68 to 1.10$)$ & 0.84 (0.65 to 1.09$)$ & \\
\hline \multirow[t]{2}{*}{ Hispanic } & 48.1 & Hand-held ban & 0.64 (0.55 to 0.73 ) & 0.61 (0.51 to 0.73 ) & 0.63 (0.54 to 0.74 ) & \\
\hline & & Texting ban & & 1.09 (0.94 to 1.25$)$ & 1.01 (0.89 to 1.16$)$ & \\
\hline \multirow[t]{2}{*}{ Others } & 49.0 & Hand-held ban & 0.62 (0.50 to 0.77$)$ & 0.62 (0.49 to 0.79$)$ & 0.64 (0.53 to 0.77$)$ & \\
\hline & & Texting ban & & 1.01 (0.78 to 1.30$)$ & 0.95 (0.73 to 1.23$)$ & \\
\hline Location & & & & & & 0.8190 \\
\hline \multirow[t]{2}{*}{ Urban } & 53.0 & Hand-held ban & 0.61 (0.56 to 0.66$)$ & 0.60 (0.55 to 0.65$)$ & 0.60 (0.54 to 0.66$)$ & \\
\hline & & Texting ban & & 1.05 (0.98 to 1.13$)$ & 1.01 (0.95 to 1.07 ) & \\
\hline \multirow[t]{2}{*}{ Rural } & 54.8 & Hand-held ban & 0.62 (0.49 to 0.79 ) & 0.64 (0.50 to 0.82 ) & 0.66 (0.51 to 0.86$)$ & \\
\hline & & Texting ban & & 0.92 (0.76 to 1.12$)$ & 0.91 (0.74 to 1.13 ) & \\
\hline
\end{tabular}

${ }^{*}$ This is the percentage of respondents who reported to engage in the behaviour out of total number who responded to the questions pertaining to hand-held cellphone conversations in the demographic group.

†The outcome was whether or not the driver self-reported to converse on a hand-held cellphone in the 30 days prior to survey. The exposure was the cellphone legislation. The RR presented compares drivers exposed to the ban to those who were not exposed; while the models contained several variables, only the RR pertaining to the universal hand-held ban and universal texting ban were shown for ease of presentation. Model 1 contained universal hand-held ban (binary) only. Model 2 contained variables for the universal hand-held ban (binary), universal texting ban (binary), and year of survey. Model 3 contained all terms from Model two and additionally controlled for sex, age group, race/ethnicity, marital status, education and household income. In Model 3 , if the model was for a particular characteristic it was not adjusted for that characteristic (example: if a model was for male sex, it was not adjusted for sex).

$\ddagger$ A fourth model containing variables from Model 2, driver characteristic, and an interaction term between the legislative ban and the driver characteristic were run to formally test for sub-group differences. The $p$-value presented is for the interaction term between the presence of the universal hand-held ban and the driver characteristic. While the models contained several variables, only the $p$-value was shown for ease of presentation.

while driving legislation. ${ }^{3}$ Also, these specific laws apply to all licensed drivers. It is possible that the uniformity of the association seen is because virtually everyone is affected by this legislation.
However, it is not completely clear why universal hand-held bans were associated with lower self-reported hand-held cellphone conversations, while universal texting bans generally were not associated with lower 
self-reported texting (excluding males and other racial/ ethnic groups). While the exact reasons are unknown, this discrepancy may be a result of enforcement. Perhaps drivers abide universal hand-held calling bans more than texting bans because hand-held calling bans are more enforced by police. Previous research suggests that citations for hand-held cellphone conversations were issued more frequently than texting while driving citations in several states. ${ }^{40}$ It may also be that hand-held bans are easier to enforce. While no study, to the authors' knowledge, has specifically determined if there are barriers to enforcing cellphone laws by police, it may be easier for law enforcement to identify drivers talking on a handheld cellphone as opposed to those texting discretely. It is well established in the literature that if individuals perceive that they will receive a citation, they are more likely to alter their driving behaviour. ${ }^{41}$ Research indicates that $>50 \%$ of drivers feel that if they use a cellphone while driving, they will receive a citation. ${ }^{3}$

\section{Limitations}

One of the inherent limitations of this analysis was that the outcome relied on self-reported driver behaviour. Self-reported behaviours may not necessarily translate into what drivers actually 'do'. Therefore, there is no way to determine if the actual driving behaviours were affected. National surveys have shown that drivers often disagree with cellphone use while driving but still engage in the behaviour. ${ }^{3}$ Drivers could have misreported the frequency or occasions in which they engaged in cellphone behaviours while driving. Because so many drivers acknowledge that cellphone use while driving can be dangerous, respondents could have purposefully biased their responses to be more socially acceptable. Also, the survey is representative of US households and not necessarily all US drivers. Additionally, this analysis did not account for law enforcement efforts in states as this information was unknown; although this study did account for state correlations among drivers, so enforcement may have been partially controlled. Additionally, Illinois and New Jersey's young driver all cellphone bans apply to drivers $<21$ years of age and may have applied to some drivers in this analysis. Because so few drivers were affected by this, models were not adjusted for this ban. Also, drivers' cellphone behaviours were based on a limited number of questions, so driver behaviour may not have been fully captured. Because of the cross-sectional nature of this analysis, no causal relationships between cell phone legislation and self-reported behaviour can be made. Drivers in states with legislation could be fundamentally different (ie, practice safer driving behaviours) that those that do not have this legislation. Additionally, numerous models were run and statistical significance could have been determined by chance.

\section{CONCLUSION}

The findings of this analysis showed that cellphone use while driving legislation, particularly universal hand-held calling bans, were associated with lower self-reported hand-held cellphone conversations across all groups of drivers. As this relationship was not seen between universal texting bans and texting behaviours, the findings suggest that more interventional work targeting all drivers is needed for texting while driving. Educational or media campaigns, effective interventions, targeted enforcement or possibly even technological advances such as cars, cellphone applications or programming which alter/limit cellphone capabilities at certain speeds/conditions, may be needed to dissuade drivers from engaging in this risky driving behaviour.

Contributors MZ conceived the study and obtained the data. TMR processed the data, performed the analysis and drafted the manuscript. MZ and HC provided technical support and contributed to the intellectual content of the manuscript. All authors had full access to the data in the study and take responsibility for the integrity of the data and the accuracy of the data analysis. All authors contributed to the manuscript preparation and approved the final version.

Funding TMR and MZ received support from National Institutes of Health grants R01HD074594, R21HD085122 and R01AG050581; and Centers for Disease Control and Prevention grants R49 CE002109. The funding agencies had no role in the design of the study, collection, analysis or interpretation of the results, or in the writing of this manuscript.

Competing interests None declared.

Patient consent for publication Not required.

Ethics approval This study was approved by the West Virginia University Institutional Review Board.

Provenance and peer review Not commissioned; externally peer reviewed.

Data sharing statement The data that support the findings of this study may be available upon request from the American Automobile Association Foundation for Traffic Safety. Data sets pertaining to legislation may be obtained from the Corresponding Author upon reasonable request.

Open access This is an open access article distributed in accordance with the Creative Commons Attribution Non Commercial (CC BY-NC 4.0) license, which permits others to distribute, remix, adapt, build upon this work non-commercially, and license their derivative works on different terms, provided the original work is properly cited, appropriate credit is given, any changes made indicated, and the use is non-commercial. See: http://creativecommons.org/licenses/by-nc/4.0/.

\section{REFERENCES}

1. Pew Research Center. Smartphone ownership and internet useage continues to climb in emerging economies. 2016 http://www. pewglobal.org/2016/02/22/smartphone-ownership-and-internetusage-continues-to-climb-in-emerging-economies/ (Accessed 12 Dec 2016).

2. National Highway Traffic Safety Administration. Traffic safety facts: driver electronic device use in 2014. 2015 www-nrd.nhtsa.dot.gov/ Pubs/812197.pdf (Accessed 2 Jan 2016).

3. Tison J, Chaudhary NK, Cosgrove L. National phone survey on distracted driving attitudes and behaviors. $2012 \mathrm{http}: / / \mathrm{ntl}$. bts.gov/lib/ 45000/45700/45720/811555.pdf (Accessed 12 Dec 2013).

4. Chen $Q$, Yan Z. New evidence of impacts of cell phone use on driving performance. International Journal of Cyber Behavior, Psychology and Learning 2013;3:46-61.

5. Collet C, Guillot A, Petit C. Phoning while driving I: a review of epidemiological, psychological, behavioural and physiological studies. Ergonomics 2010;53:589-601.

6. Collet C, Guillot A, Petit C. Phoning while driving II: a review of driving conditions influence. Ergonomics 2010;53:602-16.

7. McCartt AT, Hellinga LA, Bratiman KA. Cell phones and driving: review of research. Traffic Inj Prev 2006;7:89-106.

8. Caird JK, Willness CR, Steel P, et al. A meta-analysis of the effects of cell phones on driver performance. Accid Anal Prev 2008;40:1282-93.

9. Lansdown TC. Individual differences and propensity to engage with in-vehicle distractions - A self-report survey. Transp Res Part F Traffic Psychol Behav 2012;15:1-8. 
10. Insurance Institute for Highway Safety. Distracted driving. 2017 http://www.iihs.org/iihs/topics/laws/cellphonelaws?topicName= distracted-driving (Accessed 8 Mar 2017).

11. Cheng $\mathrm{C}$. The effect of cellphone bans on driver behavior: accidents and casualties, Department of Economics Texas A\&M University. 2012 http://econweb.tamu.edu/common/files/papers/JMPaper_ Cheng.pdf (Accessed 2 Jan 2016).

12. Foss RD, Goodwin AH, McCartt AT, et al. Short-term effects of a teenage driver cell phone restriction. Accid Anal Prev 2009;41:419-24.

13. Goodwin AH, O'Brien NP, Foss RD. Effect of North Carolina's restriction on teenage driver cell phone use two years after implementation. Accid Anal Prev 2012;48:363-7.

14. McCartt AT, Braver ER, Geary LL. Drivers' use of handheld cell phones before and after New York State's cell phone law. Prev Med 2003;36:629-35

15. McCartt AT, Geary LL. Longer term effects of New York State's law on drivers' handheld cell phone use. Inj Prev 2004;10:11-15.

16. McCartt AT, Hellinga LA. Longer-term effects of Washington, DC, law on drivers' hand-held cell phone use. Traffic Inj Prev 2007;8:199-204.

17. McCartt AT, Hellinga LA, Strouse LM, et al. Long-term effects of handheld cell phone laws on driver handheld cell phone use. Traffic Inj Prev 2010;11:133-41.

18. Rudisill TM, Zhu M. Hand-held cell phone use while driving legislation and observed driver behavior among population subgroups in the United States. BMC Public Health 2017;17:437.

19. Zhu M, Rudisill TM, Heeringa S, et al. The association between handheld phone bans and the prevalence of handheld phone conversations among young drivers in the United States. Ann Epidemiol 2016;26:833-7. e831.

20. Braitman KA, McCartt AT. National reported patterns of driver cell phone use in the United States. Traffic Inj Prev 2010;11:543-8.

21. Mathew AE, Houry D, Dente CJ, et al. Texting while driving: does the new law work among healthcare providers? West J Emerg Med 2014;15:604-8

22. Qiao N, Bell TM. State all-driver distracted driving laws and high school students' texting while driving behavior. Traffic Inj Prev 2016;17:5-8.

23. Rudisill TM, Zhu M. The association between states' texting regulations and the prevalence of texting while driving among U.S. high school students. Ann Epidemiol 2015;25:888-93.

24. Rudisill TM, Smith $\mathrm{G}$, Chu H, et al. Cellphone Legislation and SelfReported Behaviors Among Subgroups of Adolescent U.S. Drivers. J Adolesc Health 2018;62:618-25.

25. West R, French D, Kemp R, et al. Direct observation of driving, self reports of driver behaviour, and accident involvement. Ergonomics 1993;36:557-67.
26. Parada MA, Cohn LD, Gonzalez E, et al. The validity of self-reported seatbelt use: Hispanic and non-Hispanic drivers in El Paso. Accid Anal Prev 2001;33:139-43.

27. Blanchard RA, Myers AM, Porter MM. Correspondence between selfreported and objective measures of driving exposure and patterns in older drivers. Accid Anal Prev 2010;42:523-9.

28. Rhodes N, Pivik K. Age and gender differences in risky driving: the roles of positive affect and risk perception. Accid Anal Prev 2011;43:923-31.

29. Zhang W, Gkritza K, Keren N, et al. Age and gender differences in conviction and crash occurrence subsequent to being directed to lowa's driver improvement program. J Safety Res 2011:42:359-65.

30. Romano E, Voas R, Tippetts S. Stop sign violations: the role of race and ethnicity on fatal crashes. J Safety Res 2006;37:1-7.

31. Romano E, Tippetts S, Voas R. Fatal red light crashes: the role of race and ethnicity. Accid Anal Prev 2005;37:453-60.

32. Rakauskas ME, Ward NJ, Gerberich SG. Identification of differences between rural and urban safety cultures. Accid Anal Prev 2009;41:931-7.

33. Romano E, Fell J, Voas R. The role of race and ethnicity on the effect of graduated driver licensing laws in the United States. Ann Adv Automot Med 2011;55:51-61.

34. Pew Research Center. Cellphones and American Adults. 2010 http:// pewinternet.org/Reports/2010/Cell-Phones-and_American-Adults. aspx (Accessed 6 Jan 2017).

35. American Automobile Association Foundation for Traffic Safety. Traffic Safety Culture Index. 2014 https://aaafoundation.org/2014traffic-safety-culture-index/.

36. Govenors Highway Safety Association. Distracted driving laws. 2016 http://www.ghsa.org/html/stateinfo/laws/cellphone_laws.html (Accessed 8 Aug 2016).

37. Handsfreeinfo. Index: cellphone laws legislation by state. $2016 \mathrm{http}: / /$ handsfreeinfo.com/index-cell-phone-laws-legislation-by-state/ (Accessed 2 Jan 2013).

38. Zou G. A modified poisson regression approach to prospective studies with binary data. Am J Epidemiol 2004;159:702-6.

39. Governors Highway Safety Association. Distracted driving: survey

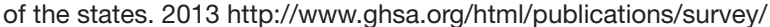
distraction2013.html (Accessed 8 Aug 2016).

40. Rudisill TM, Zhu M. Who actually receives cell phone use while driving citations and how much are these laws enforced among states? A descriptive, cross-sectional study. BMJ Open 2016;6:e011381.

41. Stanojević $P$, Jovanović $D$, Lajunen $T$. Influence of traffic enforcement on the attitudes and behavior of drivers. Accid Anal Prev 2013;52:29-38. 